\title{
Aortic uncrossing procedure: When the right becomes left
}

\author{
Sameh M. Said, MBBCh, MD, FACS, ${ }^{a}$ Gamal Marey, MD, ${ }^{\mathrm{a}}$ Luke Jakubowski, MD, ${ }^{\mathrm{b}}$ and \\ Carlos Miranda, MD, ${ }^{\mathrm{c}}$ Minneapolis, Minn, and Fargo, ND
}

\footnotetext{
From the ${ }^{\mathrm{a}}$ Division of Pediatric Cardiovascular Surgery and ${ }^{\mathrm{b}}$ Department of Otolaryngology, Head, and Neck Surgery, Masonic Children's Hospital, University of Minnesota, Minneapolis, Minn; and 'Sanford Pediatric Cardiology, Fargo, ND.

Disclosures: Dr Said is a consultant for Cryolife. All other authors reported no conflicts of interest.

The Journal policy requires editors and reviewers to disclose conflicts of interest and to decline handling or reviewing manuscripts for which they may have a conflict of interest. The editors and reviewers of this article have no conflicts of interest.

Received for publication Sept 8, 2020; accepted for publication Sept 17, 2020; available ahead of print Sept 22, 2020.

Address for correspondence: Sameh M. Said, MBBCh, MD, FACS, Division of Pediatric Cardiovascular Surgery, Masonic Children's Hospital, University of Minnesota, 2450 Riverside Ave S, East Building, MB 539, Minneapolis, MN 55454 (E-mail: ssaid@umn.edu).

JTCVS Techniques 2020;4:239-42

2666-2507

Copyright (C) 2020 The Authors. Published by Elsevier Inc. on behalf of The American Association for Thoracic Surgery. This is an open access article under the CC BY-NC-ND license (http://creativecommons.org/licenses/bync-nd/4.0/).

https://doi.org/10.1016/j.xjtc.2020.09.017
}

- Video clip is available online.

The first description of aortic uncrossing was in 1984 by Planché and LaCoeur-Gayet. ${ }^{1}$ This procedure allows translocation of the retroesophageal aorta (Figure 1, $A$ and $B$ ) anterior to the trachea (Figure 1, $C$ and $D$ ), thus alleviating the airway compression. The aortic arch then changes from being right sided to a left sided, relative to the airway. We present the technique in a 7-month-old girl with a vascular ring consisting of a right aortic arch with mirror-image branching and a left-sided descending aorta and left ligamentum, using normothermic cardiopulmonary bypass (CPB) (Figure 2).

\section{SURGICAL TECHNIQUE (VIDEO 1)}

Intraoperative bronchoscopy was performed to evaluate the airway (Figure 3,A). After sternotomy and adequate mobilization of ascending aorta, arch and branches, CPB was initiated via dual arterial cannulation (right common carotid and descending aorta) at normothermia. Left ligamentum arteriosum was divided. A side-biting clamp was placed on the proximal descending aorta, and another 1 just after the takeoff of the right subclavian artery. The proximal arch was then transected and case was obtained.

\section{DISCUSSION}

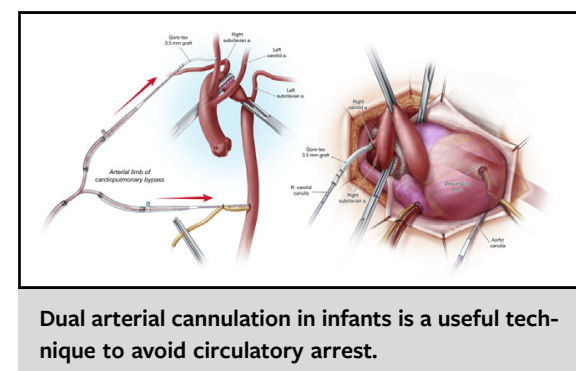

CENTRAL MESSAGE

Aortic translocation for circum-

flex aorta causing tracheobron-

chial compression can be

performed safely on a beating

heart using normothermic car-

diopulmonary bypass via dual

arterial cannulation.

See Commentary on page 243.

the proximal end was over sewn. The arch was then brought from its retroesophageal position anteriorly where it was anastomosed in an end-to-side fashion to the distal ascending aorta (Figure 4). Clamps were removed and the patient was weaned off CPB. Repeat bronchoscopy showed complete relief of airway compression (Figure 3, B). The patient was extubated in the operating room and the postoperative course was uneventful. Permission from the parents to publish this

Circumflex aorta should be addressed when present with other vascular ring variants to avoid recurrence of symptoms and repeat operation. ${ }^{2}$ The procedure can be performed safely on a beating heart without circulatory/ cardioplegic arrest ${ }^{3}$ using the technique of dual arterial cannulation (Figure 5). ${ }^{4}$ We used the same size cannula for both upper and lower body perfusion, leaving it up to each organ's vascular resistance to regulate its own blood flow. We did not feel the need for concomitant 


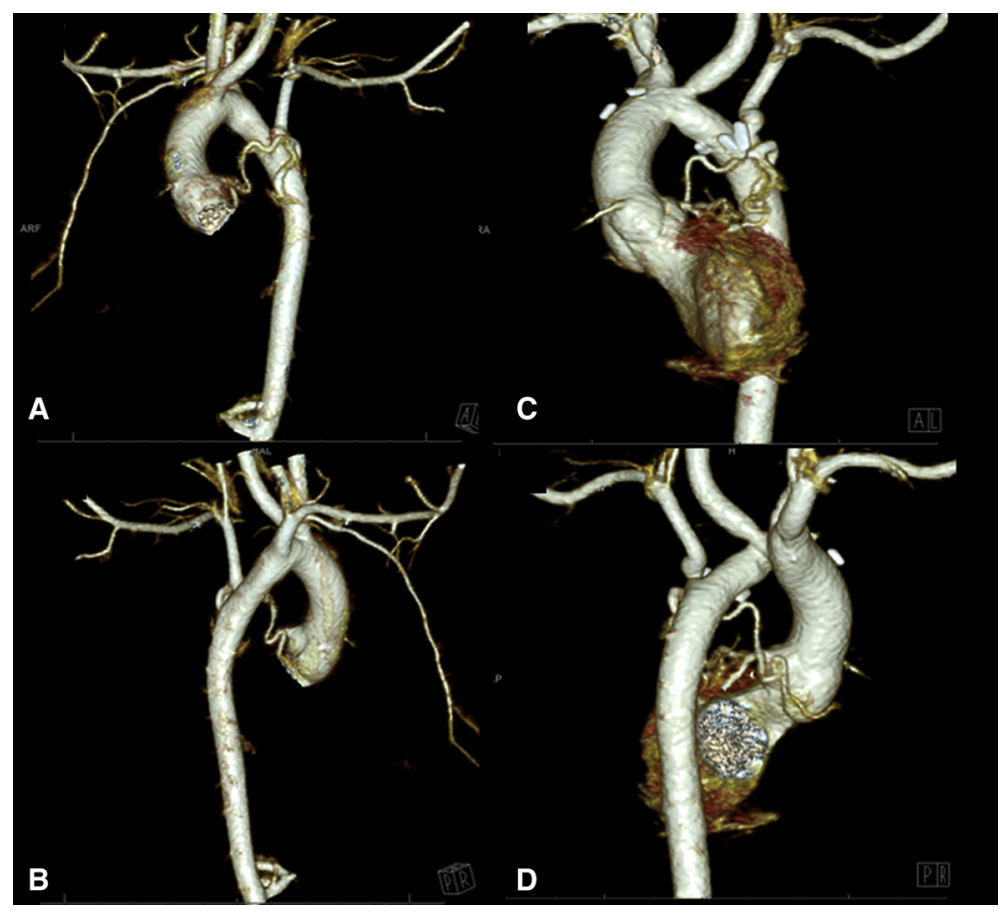

FIGURE 1. A through D, Computed tomography scan with 3-dimensional reconstruction, front and back views, comparing the circumflex aorta before (A and $\mathrm{B})$ and after (C and D) the uncrossing.

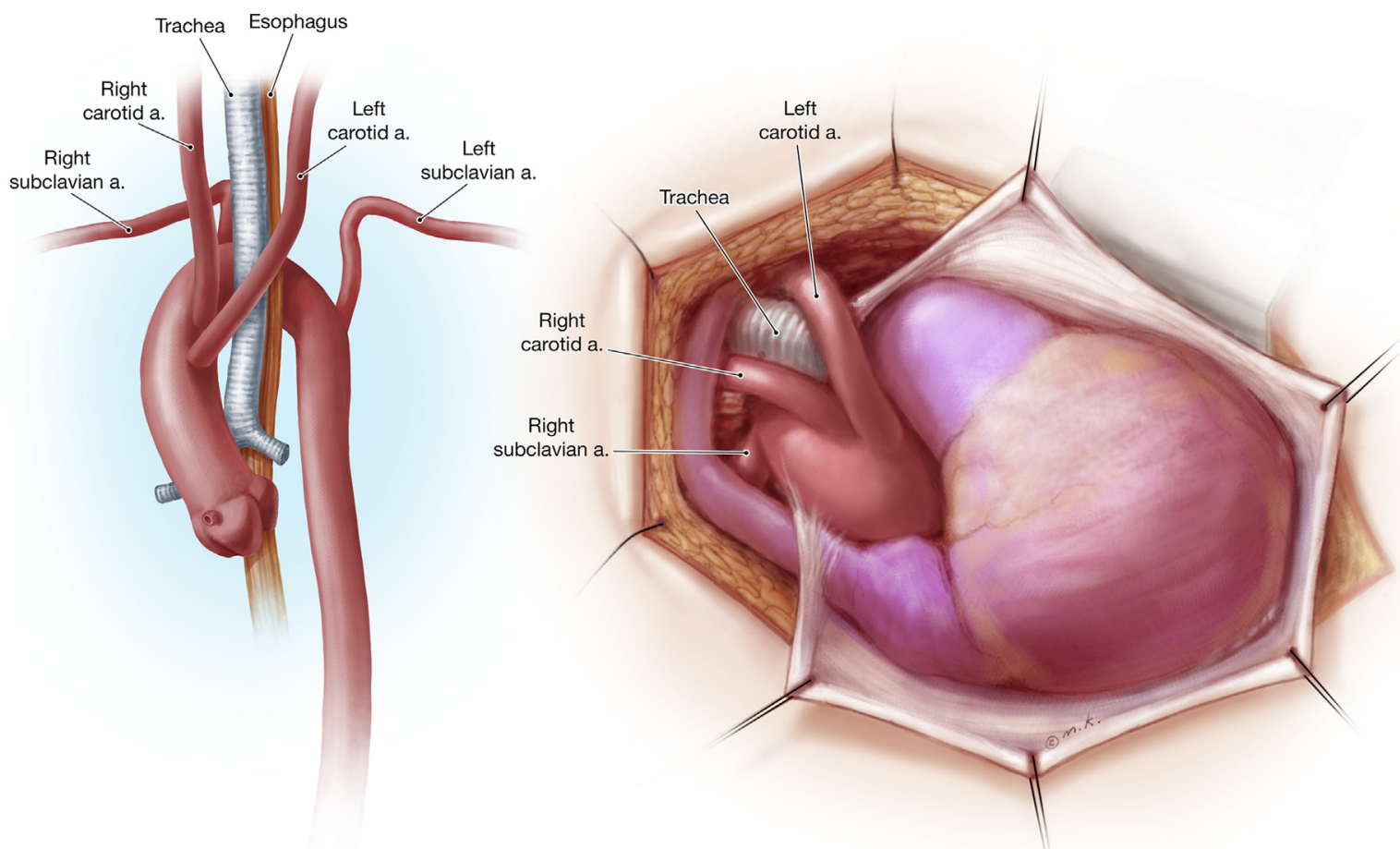

FIGURE 2. Illustration showing the anatomy of the aortic arch in the current case. Right aortic arch with retroesophageal circumflex aorta. The order of branching are left common carotid, followed by right common carotid, right subclavian, and left subclavian arteries. Trachea and esophagus are encircled between the left ligamentum, right arch, and retroesophageal circumflex aorta. 

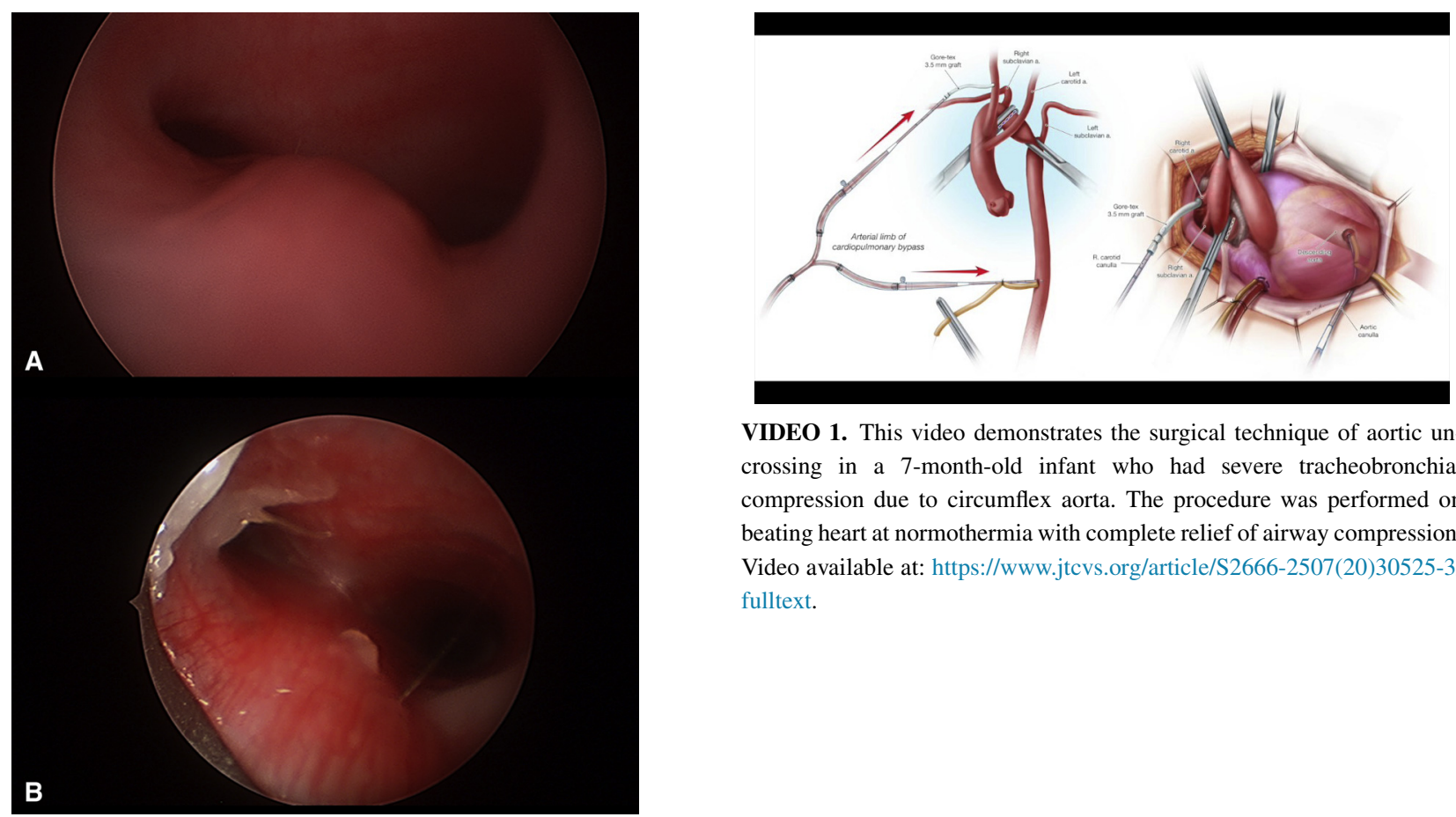

VIDEO 1. This video demonstrates the surgical technique of aortic uncrossing in a 7-month-old infant who had severe tracheobronchial compression due to circumflex aorta. The procedure was performed on beating heart at normothermia with complete relief of airway compression. Video available at: https://www.jtcvs.org/article/S2666-2507(20)30525-3/ fulltext.

FIGURE 3. A and B, Intraoperative bronchoscopy before (A) and after (B) the uncrossing procedure showing complete relief of the tracheobronchial compression.

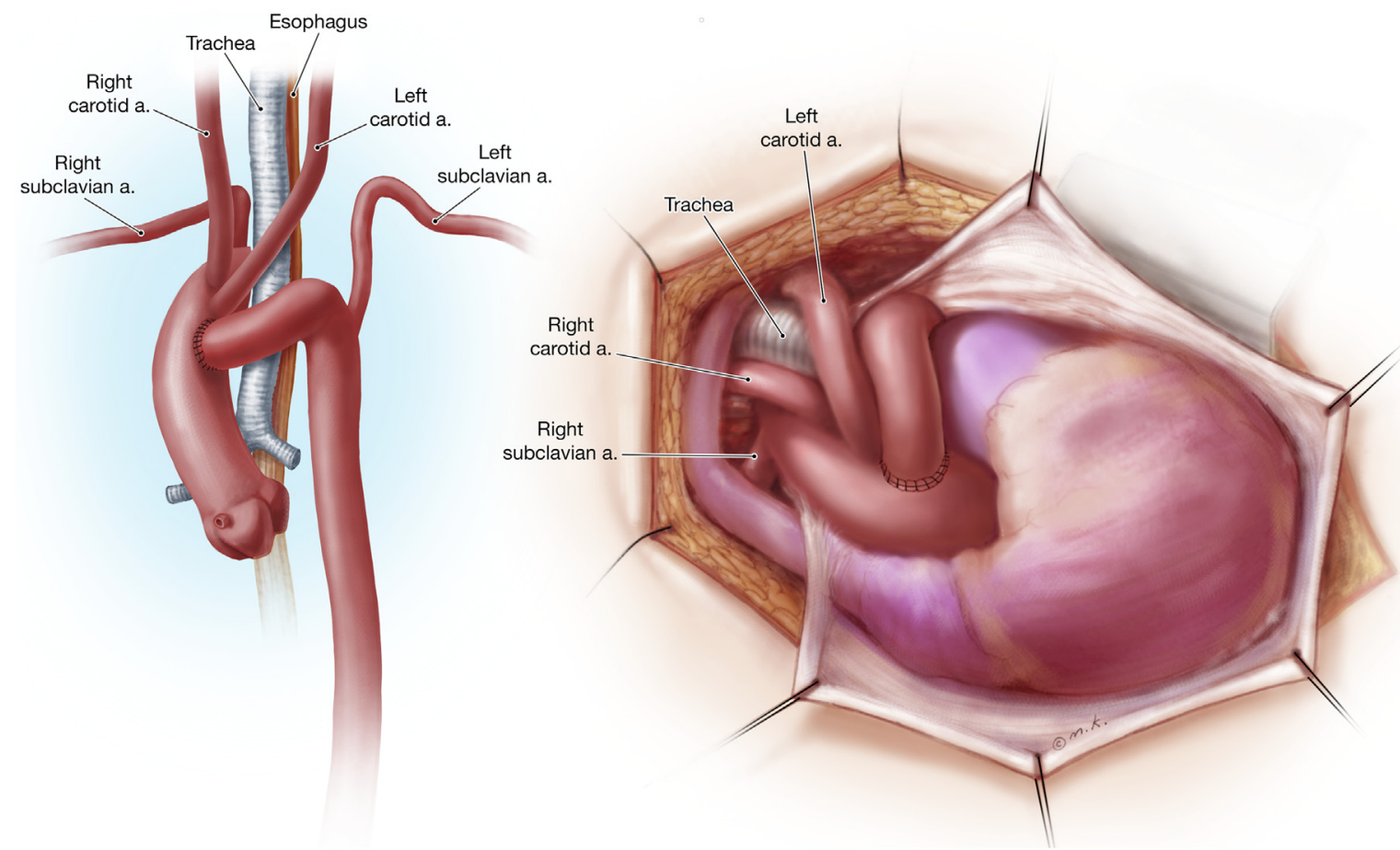

FIGURE 4. Illustration showing the postoperative result after the uncrossing procedure where the right arch simply becomes a left arch. 


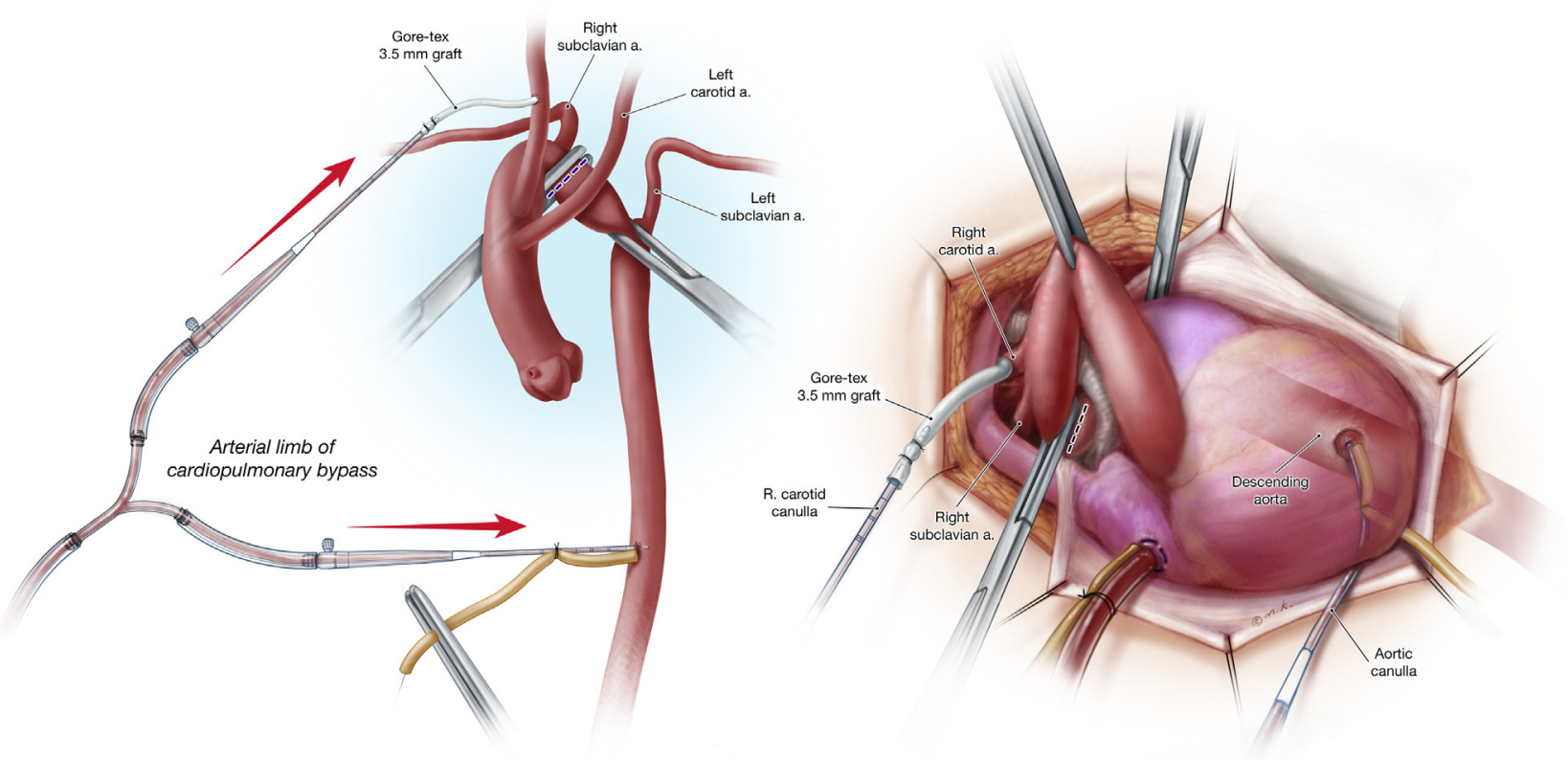

FIGURE 5. Dual arterial cannulation in infants is a useful technique to avoid circulatory arrest.

tracheobronchopexy due to the complete resolution of airway compression. ${ }^{5}$

\section{References}

1. Planché C, LaCoeur-Gayet F. Aortic uncrossing for compressive circumflex aorta: 3 cases. Press Med. 1984;13:1331-2.

2. Backer CL, Mongé MC, Russell HM, Popescu AR, Rastatter JC, Costello JM. Reoperation after vascular ring repair. Semin Thorac Cardiovasc Surg Pediatr Card Surg Апnu. 2014;17:48-55.
3. Binsalamah ZM, Chacon-Portillo MA, Sanyahumbi A, Adachi I, Heinle JS, Fraser CD Jr, et al. Circumflex aorta with double aortic arch in an infant. J Card Surg. 2018;33:292-5.

4. Kreuzer M, Sames-Dolzer E, Benedikt P, Mair R, Mair R. Double-arterial cannulation during aortic arch reconstruction in pediatric patients. Multimed Man Cardiothorac Surg. 2018;17:2018.

5. Kamran A, Friedman KG, Jennings RW, Baird CW. Aortic uncrossing and tracheobronchopexy corrects tracheal compression and tracheobronchomalacia associated with circumflex aortic arch. J Thorac Cardiovasc Surg Tech. 2020; 3:796-804. 